\title{
INTEGRIDADE DAS MEMBRANAS PLASMÁTICA, NUCLEAR E MITOCONDRIAL DE ESPERMATOZÓIDES OVINOS CRIOPRESERVADOS COM ETILENO GLICOL ${ }^{1}$
}

\author{
INTEGRITY OF SPERM PLASM MEMBRANE, NUCLEUS AND MITOCHONDRIA \\ AFTER FREEZING RAM SEMEN WITH ETHYLENE GLYCOL
}

\section{Luciana Bignardi de Soares Brisola ${ }^{2}$ Jairo Pereira Neves $^{3}$ Paulo Bayard Dias Gonçalves ${ }^{3}$ João Francisco Coelho de Oliveira ${ }^{4}$ Marcelo Marcos Montagner $^{5}$}

RESUMO

Este trabalho foi conduzido com o objetivo de avaliar o sêmen ovino criopreservado com etileno glicol em relação ao glicerol, quanto à motilidade progressiva e vigor e, especialmente, quanto à integridade das membranas plasmática, nuclear e mitocondrial. Foram utilizados ejaculados de sêmen provenientes de dois carneiros da raça Ile-de-France, com padrões mínimos de volume $(0,5 \mathrm{ml})$, turbilhonamento (2 de 0-5), motilidade progressiva (65\%), vigor (3 de 0-5), aspecto (cremoso fino, $3 \times 10^{6}$ espermatozóides/mm3) e células normais (80\%). Um total de 25 pools foi dividido em duas alíquotas, as quais foram, posteriormente, congeladas com etileno glicol a 0,5M ou glicerol a $0,72 \mathrm{M}$ em pellets. Os parâmetros utilizados, para avaliar o desempenho dos crioprotetores, foram a motilidade progressiva, vigor espermático e integridade do acrossomo e das membranas plasmáticas dos espermatozóides. A motilidade e vigor foram aferidos no sêmen fresco, resfriado, descongelado, mantido a $38^{\circ} \mathrm{C}$ por 5 horas de incubação (TTL-teste de termorresistência lento) e à temperatura de $45^{\circ} \mathrm{C}$ por 30 minutos (TTR- teste de termorresistência rápido). Não houve diferença entre o etileno glicol e o glicerol para a avaliação da morfologia do acrossomo, motilidade progressiva e vigor. As células espermáticas criopreservadas com etileno glicol apresentaram maior integridade das membranas plasmática, nuclear e mitocondrial do espermatozóide. O etileno glicol é mais eficiente do que o glicerol para preservar a integridade das membranas espermáticas na congelação de sêmen ovino.

Palavras-chave: sêmen, etileno glicol, membranas, ovinos.

\section{SUMMARY}

The aim of the present experiment was to evaluate the effect of ethylene glycol, in relation to glycerol, as a cryoprotective agent for preserving ovine spermatic cells. The semen had to present a minimal quality to be used, regarding volume $(0.5 \mathrm{ml})$, wave motion (score of 2 , from 0 to 5$)$, percentage of progressively motile spermatozoa (65\%), rate of progressive motility (score of 3, from 0 to 5), sperm cell concentration $\left(3 \times 10^{6}\right.$ cells $\left./ \mathrm{mm}^{3}\right)$ and normal sperm morphology (80\%). Each pool of semen from ejaculates of two rams was divided into two equal subsamples. One subsample was frozen with ethylene glycol and the other with glycerol. The parameters used to evaluate the semen were sperm motility, vigor, acrossome status and membrane integrity. Sperm motility was evaluated in fresh semen, cooled semen, frozen semen, after 5 hours at $38^{\circ} \mathrm{C}$ or after 30 minutes at $45^{\circ} \mathrm{C}$. No difference was observed between ethylene glycol and glycerol for acrossome status and sperm motility. The sperm cells that were preserved with ethylene glycol showed more integrity of the plasmatic, nuclear and mitochondrial membranes. From the viewpoint of cell membrane integrity, it can be concluded that ethylene glycol gives higher protection to the sperm cell than glycerol.

Key words: semen, ethylene glycol, membrane integrity, ram.

\section{INTRODUÇÃO}

A inseminação artificial (IA) é a técnica mais difundida e importante para o melhoramento

\footnotetext{
${ }^{1}$ Trabalho realizado com suporte financeiro da FAPERGS, CNPq e EMBRAPA.

${ }^{2}$ Médico Veterinário, autônomo, Palotina, PR.

${ }^{3}$ Professor Titular, Doutor, Departamento de Clínicas de Grandes Animais, Centro de Ciências Rurais (CCR), Universidade Federal de Santa Maria (UFSM), Santa Maria, RS, 97105-900. E-mail: jpneves@lince.hcv.ufsm.br. Autor para correspondência.

${ }^{4}$ Professor Assistente, MSc., Departamento de Clínica de Grandes Animais, CCR, UFSM.

${ }^{5}$ Médico Veterinário, aluno de mestrado do Programa de Pós-graduação, UFSM. 
genético. Através da IA, grande número de fêmeas podem ser inseminadas com sêmen de um reprodutor com alto valor genético, possibilitando elevar, a curto prazo e com menor custo, a qualidade genética do rebanho. Desde a primeira preservação criobiológica de sêmen ovino, realizada por EMMENS \& BLACKSHAW (1950), até o momento, não há método eficiente de preservação espermática e deposição na fêmea que proporcione percentagens de parição semelhantes àqueles encontrados com monta natural ou quando se utiliza inseminação por via laparoscópica. Esta última técnica tem sido restrita a rebanhos de elevado valor genético em função do elevado custo com sincronização de cios, equipamentos e mão-de-obra especializada. Não haveria esse custo elevado, se a IA com sêmen congelado fosse por via cervical com satisfatórios índices de parição. Portanto, é importante desenvolver um método eficaz de criopreservação de sêmen ovino. Por isso, as investigações sobre os crioprotetores e sua ação sobre as células espermáticas são fundamentais.

Os resultados de prenhez dos animais que são submetidos a IA por via cervical atingem índices máximos de 40\% (MAXWELL \& SALAMON, 1993). A baixa fertilidade do sêmen ovino congelado é atribuída, em grande parte, às alterações sofridas na estrutura das membranas plasmática, acrossomal e mitocondrial durante o resfriamento, congelação e descongelação (PARKS \& GRAHAM, 1992). A utilização de corantes biológicos permite avaliar a integridade do acrossomo e da membrana plasmática da célula espermática nas diferentes espécies (GREEN, 1992; VÁSQUEZ et al., 1992; CROSS \& WATSON, 1994).

O presente trabalho teve por objetivo principal avaliar o sêmen ovino criopreservado com etileno glicol ante o glicerol quanto à motilidade $\mathrm{e}$ vigor e, especialmente, quanto à integridade das membranas plasmática, nuclear e mitocondrial.

\section{MATERIAL E MÉTODOS}

Foram utilizados dois carneiros da raça Ile-de-France, com dois anos de idade, previamente submetidos à avaliação andrológica, em bom estado sanitário e nutricional, mantidos em regime de semiconfinamento. Um total de 25 pools de sêmen foi obtido a partir de coletas com vagina artificial e auxílio de manequim. Após a coleta, o sêmen foi colocado em banho-maria à temperatura de $30^{\circ} \mathrm{C}$, quando se procedeu a sua análise. Os ejaculados que foram utilizados apresentaram os seguintes padrões mínimos: volume de $0,5 \mathrm{ml}$, turbilhonamento nível 2 (0-5), motilidade progressiva de $65 \%$, vigor $3(0-5)$, aspecto cremoso fino $\left(3 \times 10^{6}\right.$ espermatozóides $\left./ \mathrm{mm}^{3}\right)$ e $80 \%$ de células normais. A congelação do sêmen foi realizada segundo a técnica de EVANS \& MAXWELL (1987), modificada por MORAES (1996) para pellets com volume de $130 \mu \mathrm{l}$, correspondendo a uma concentração mínima de $100 \times 10^{6}$ espermatozóides por dose. Utilizou-se diluente TRIS na proporção de $1+3$ (uma parte de sêmen para três de diluidor), dividido em duas alíquotas de acordo com o crioprotetor utilizado. Os diluentes continham etileno glicol $(0,5 \mathrm{M})$ e glicerol $(0,72 \mathrm{M})$. A congelação foi realizada em vapor de nitrogênio líquido, utilizando placa de acrílico de 4,0mm de espessura, mantida a uma distância de $3,0 \mathrm{~cm}$ acima do nível do nitrogênio. $\mathrm{O}$ descongelamento foi realizado em banho-maria a $38^{\circ} \mathrm{C}$ por 30 segundos, colocando-se os pellets em tubo de ensaio de vidro, contendo $0,5 \mathrm{ml}$ de solução fisiológica e agitando até completa diluição.

Para a avaliação do desempenho dos crioprotetores, a motilidade progressiva e vigor foram aferidos no sêmen fresco, resfriado, descongelado, mantido a $38^{\circ} \mathrm{C}$ por 5 horas de incubação, correspondendo ao TTL e mantido à temperatura de $45^{\circ} \mathrm{C}$ por 30 minutos de incubação, correspondendo ao TTR. Tendo em vista a avaliação da integridade do acrossomo, foram confeccionadas lâminas com esfregaços de sêmen, empregando-se posteriormente a técnica de KOVÁCS \& FOOTE (1992). No sentido de classificar as alterações acrossomáticas e a sobrevivência espermática, foram consideradas seis classes: espermatozóide vivo com acrossomo íntegro (AVI), espermatozóide vivo com acrossomo lesado (AVL), espermatozóide vivo com acrossomo ausente (AVS), espermatozóide morto com acrossomo íntegro (AMI), espermatozóide morto com acrossomo lesado (AML), espermatozóide morto com acrossomo ausente (AMS).

A integridade da membrana plasmática foi avaliada através da coloração fluorescente, utilizando-se da mistura de corantes biológicos, sondas fluorescentes, à base de diacetato de carboxifluoresceína $^{\mathrm{a}}$ (DIC) e iodeto de propídio ${ }^{\mathrm{a}}$ (IP), de acordo com o método descrito por HARRISON \& VICKERS (1990). Foram consideradas células espermáticas com membranas plasmáticas íntegras quando foi observado acúmulo de DIC (fluorescência verde) ao longo da cabeça e flagelo do espermatozóide, sem acúmulo de IP (fluorescência vermelha). Ao detectar um acúmulo de DIC na peça intermediária e acúmulo de IP somente na cabeça, consideraram-se células espermáticas com membranas plasmática e acrossomal danificadas e membranas mitocondriais intactas. Foram classificadas como células espermáticas com membranas plasmáticas 
danificadas e mitocondriais intactas ao observar um acúmulo de DIC na peça intermediária e região acrossomal e acúmulo de IP somente na cabeça do espermatozóide. Ao verificar acúmulo de DIC na região acrossomal e acúmulo de IP na cabeça e peça intermediária, as células espermáticas foram consideradas como apresentando membranas plasmática e mitocondriais danificadas e membrana acrossomal íntegra. Finalmente, ao observar acúmulo de IP na cabeça e peça intermediária, sem acúmulo de DIC, as células espermáticas foram classificadas como tendo membranas plasmáticas, acrossomal e mitocondriais danificadas.

$\mathrm{O}$ experimento foi implementado seguindo o desenho experimental em blocos casualizados. Cada pool de sêmen foi considerado um bloco e foi dividido em dois grupos, sendo que uma fração de sêmen alocada para um dos grupos foi congelada com etileno glicol e a outra fração com glicerol. Tendo em vista que os dados não apresentavam uma distribuição normal, os mesmos foram reescritos segundo seus postos (CONOVER \& IMAN, 1981), utilizando o PROC RANK no programa estatístico SAS. Os resultados foram analisados pelo PROC GLM, utilizando o seguinte modelo estatístico (NETER et al. 1985):

$$
Y_{\mathrm{ij}}=\mu+\alpha_{\mathrm{i}}+\beta_{\mathrm{j}}+(\alpha \beta)_{\mathrm{ij}}+\varepsilon_{\mathrm{ij}}
$$

onde $Y_{\mathrm{ij}}$ são os parâmetros estudados submetidos à transformação para obter uma distribuição possível de ser analisada por métodos paramétricos, $\mu$ é a constante comum a todas as observações, $\alpha_{i}$ é o efeito do grupo (glicerol ou etileno glicol), $\beta_{\mathrm{j}}$ é o efeito do bloco (pool de sêmen), os efeitos do bloco são aleatórios, $(\alpha \beta)_{\mathrm{ij}}$ é a interação entre os fatores, tendo sido retirado do modelo quando a interação não foi significativa, e $\varepsilon_{\mathrm{ij}}$ é o efeito do erro experimental.

\section{RESULTADOS E DISCUSSÃO}

A avaliação da motilidade e vigor espermático no transcorrer do processo de congelação, como após os testes de termorresistência, utilizando como crioprotetores o etileno glicol $(0,5 \mathrm{M})$, forneceu índices similares àqueles resultantes com o emprego do glicerol $(0,72 \mathrm{M})$, conforme demonstrado nas figuras 1 e 2 . Os testes de termorresistência avaliam o comportamento das células espermáticas após período de incubação, confrontando a resistência à temperatura e o tempo de incubação. Em relação à morfologia acrossomal, é possível afirmar que não houve diferença significativa entre os dois crioprotetores empregados para as classes AVI, AVL,

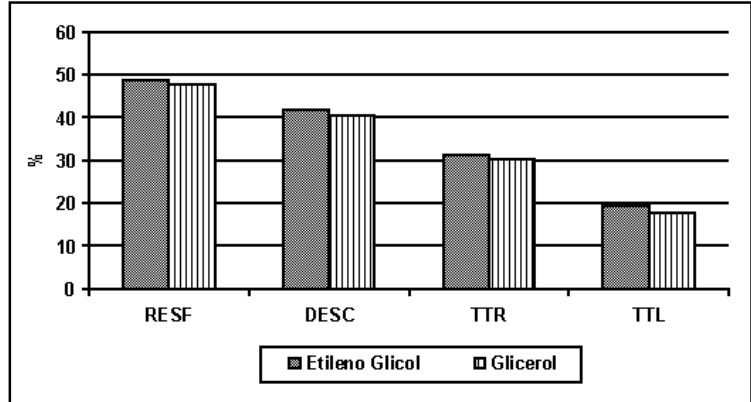

Figura 1 - Percentagem comparativa da motilidade espermática entre etileno glicol $(0,5 \mathrm{M})$ e glicerol $(0,72 \mathrm{M})$ avaliada no sêmen resfriado (RESF), descongelado (DESC), mantido a $46^{\circ} \mathrm{C}$ por 30 minutos (Teste de termorresistência rápido, TTR) e mantido a $38^{\circ} \mathrm{C}$ por 5 horas (Teste de termorresistência lento, TTL). Os dois crioprotetores apresentaram índices similares quanto à motilidade progressiva $(\mathrm{p}>0,05)$.

AVS, AMI, AML e AMS (Figura 3). No decorrer da avaliação das lesões acrossomáticas, pela técnica de KOVÁCS \& FOOTE (1992), observou-se que essas ocorrem similarmente tanto nas células vivas como nas mortas. A percentagem de acrossomos morfologicamente lesados, detectados por essa técnica, não ultrapassou o limite máximo de $70 \%$ proposto por EVANS \& MAXWELL (1987) para sêmen ovino submetido à congelação. Em acordo com SALAMON \& MAXWELL (1995), de que apenas 20-30\% das células espermáticas ovinas permanecem íntegras após a congelação e descongelação, os índices verificados no presente trabalho permaneceram em torno de $36 \%$ no sêmen congelado, tanto com etileno glicol, como com glicerol.

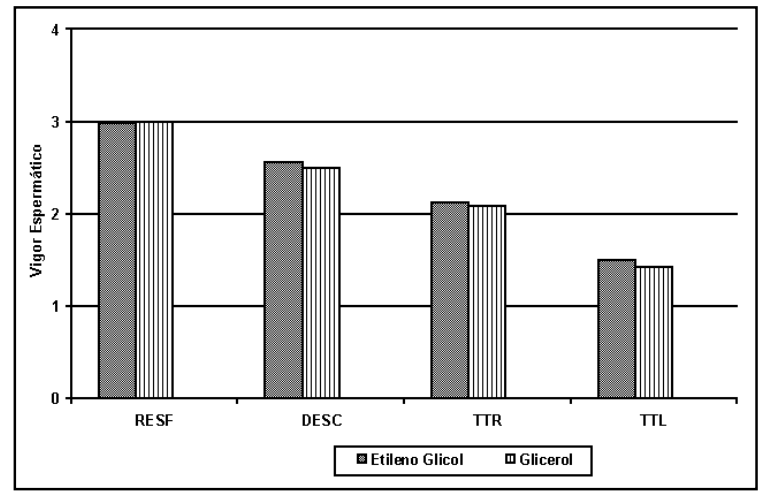

Figura 2 - Valores comparativos do vigor espermático (0-5) entre etileno glicol $(0,5 \mathrm{M})$ e glicerol $(0,72 \mathrm{M})$, avaliadas no sêmen resfriado (RESF), descongelado (DESC), mantido a $46^{\circ} \mathrm{C}$ por 30 minutos (Teste de termorresistência rápido, TTR) e mantido a $38^{\circ} \mathrm{C}$ por 5 horas (Teste de termorresistência lento, TTL). Os dois crioprotetores apresentaram índices similares quanto ao vigor $(\mathrm{p}>0,05)$. 


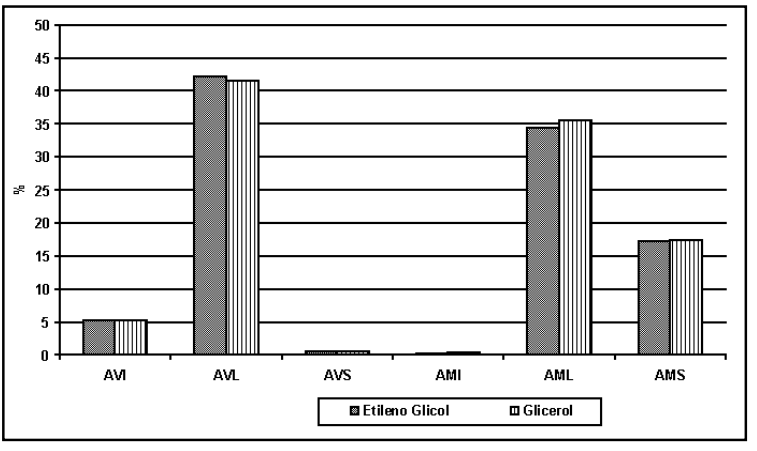

Figura 3 - Avaliação da integridade acrossomática e percentagem de células vivas e mortas utilizando como crioprotetores o etileno glicol $(0,5 \mathrm{M})$ e o glicerol $(0,72 \mathrm{M})$. Os parâmetros avaliados foram espermatozóides vivos com acrossomo íntegro (AVI), vivos com acrossomo lesado (AVL), vivos com acrossomo ausente (AVS), mortos com acrossomo íntegro (AMI), mortos com acrossomo lesado (AML) e mortos com acrossomo ausente (AMS). Quanto à integridade acrossomática e percentual de células vivas e mortas não houve diferença entre os crioprotetores testados $(\mathrm{p}>0,05)$.

Foram observadas diferenças significativas entre os dois crioprotetores empregados quanto à integridade das membranas espermáticas $(\mathrm{P}<0,001$; figura 4). As percentagens de membranas íntegras (verde), danificadas (vermelhas) e parcialmente danificadas (verde/vermelha) foram de 36,42\%; $53,64 \% ; 9,94 \%$ e $33,62 \% ; 58,44 \% ; 7,94 \%$ de membranas íntegras, respectivamente, para o etileno glicol e glicerol. A categoria que apresenta fluorescência verde ao longo de toda célula e que indica integridade das membranas está fundamentada nos achados de GARNER et al. (1986), quando propuseram o mecanismo de ação dos corantes fluorescentes, DIC e IP. Esses autores salientaram que o DIC, por ser um éster polar, não fluorescente, atravessa a membrana plasmática e, dentro da célula, é hidrolisado por esterases inespecíficas, resultando na formação de um composto impermeável à membrana plasmática que fluoresce em verde, denominado de 6-carboxifluoresceína. Ao contrário, o IP possui forte afinidade pelos ácidos nucléicos, mostrando-se impermeável à membrana plasmática, fluorescendo em vermelho somente em células com membranas danificadas. A iluminação, com luz ultravioleta e utilização do filtro para fluoresceína (luz azul), revelou espermatozóides fluorescentes de cor verde, indicando que o IP não atravessa a membrana íntegra. Na segunda categoria, que apresentou fluorescência vermelha na cabeça e peça intermediária, segundo as observações do mecanismo de ação dos corantes semelhantes aos citados anteriormente, e considerando que a cabeça e a peça intermediária do gameta masculino contém DNA, espera-se a colora-

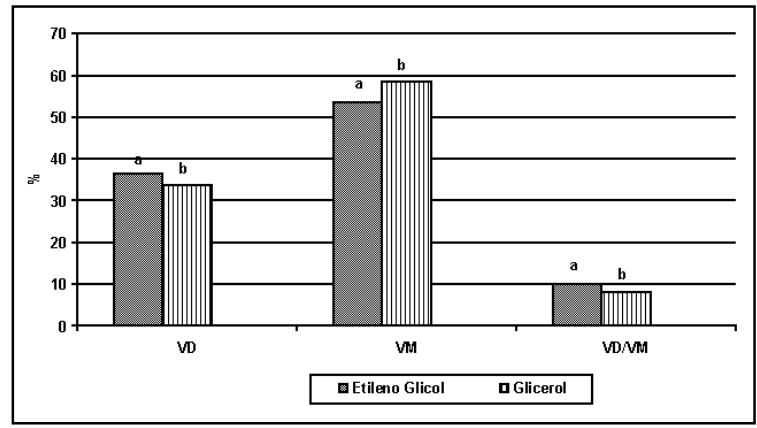

Figura 4 - Índices de integridade das membranas plasmática, nuclear e mitocondrial, com sondas fluorescentes, nos diferentes tratamentos. A categoria VD (membranas íntegras) é fluorescência verde ao longo de toda célula, a VM (membranas danificadas) é fluorescência vermelha na cabeça e peça intermediária e VD/VM (membranas parcialmente danificadas) é fluorescência verde na peça intermediária e fluorescência vermelha na cabeça do espermatozóide. A percentagem de membranas espermáticas íntegras foi superior quando foi utilizado o etileno glicol em uma concentração de $0,5 \mathrm{M}$. Letras distintas, acima de cada barra, representam diferença estatística entre os tratamentos $(\mathrm{p}<0,001)$.

ção vermelha. Lesões na membrana mitocondrial também são referidas como as principais injúrias induzidas pelo processamento de congelação e pelo choque térmico causados às células durante a preparação para a inseminação. Se a célula espermática ovina for dependente do metabolismo respiratório durante a passagem cervical, esta injúria à membrana mitocondrial pode representar um fator de limitação da fertilidade em sêmen descongelado, como afirmam WINDSOR \& WHITE (1995) e MAXWELL \& WATSON (1996).

A interpretação da terceira categoria, indicando espermatozóides que apresentavam fluorescência verde na peça intermediária, acúmulo de DIC, foi que as membranas das mitocôndrias estavam íntegras, resultado da atividade das esterases dentro das organelas. O acúmulo de IP na cabeça dos espermatozóides é indicativo da penetração do corante nas membranas plasmática e nuclear danificadas, o qual, unindo-se ao DNA do núcleo, produz uma fluorescência de coloração vermelha, revelada pela incidência da luz ultravioleta.

HOLT \& NORTH (1984 e 1986) relataram a ocorrência de alterações na organização lipídica das membranas no decorrer de diferentes fases térmicas, com modificação de sua permeabilidade. Fato semelhante foi constatado no presente experimento, utilizando sondas fluorescentes. Após os procedimentos de criopreservação, aos quais as células espermáticas foram expostas, foi observado um incremento de células com lesões nas membranas plasmáticas. Importante destacar o efeito que o 
processo de congelação exerce sobre as células espermáticas, aumentando a incidência de acrossomos danificados (KOVÁCS \& FOOTE, 1992), e mesmo aqueles espermatozóides morfologicamente considerados normais podem apresentar-se com a membrana plasmática lesada (HARRISON \& VICKERS, 1990).

A melhor preservação das membranas espermáticas, verificada nas células criopreservadas com etileno glicol, pode ser explicada pela sua maior velocidade de penetração celular, diminuindo a concentração de sais no interior dos espermatozóides, atenuando os efeitos deletérios das estruturas espermáticas (MORAES, 1996). MERYMAN et al. (1977) destacam que o etileno glicol possui a propriedade de conferir maior estabilidade às estruturas lipídicas das membranas espermáticas, protegendo as células das alterações provocadas pelo choque térmico.

Os baixos índices da inseminação artificial via cervical com sêmen congelado, obtidos em ovinos, podem ser em conseqüência de alterações provocadas nas células espermáticas durante a congelação do sêmen. Nesse experimento, foi constatado que o sêmen congelado com etileno glicol ou glicerol apresentou um decréscimo acentuado na motilidade progressiva nos testes de termorresistência, considerado por MOLINIA et al. (1994) como sendo conseqüência de um aumento no metabolismo celular de espermatozóides submetidos à congelação em decorrência da hiperatividade espermática. No entanto, houve um incremento no percentual de membranas espermáticas íntegras quando o sêmen foi congelado na presença de etileno glicol em relação ao glicerol. Considerando os resultados obtidos, conclui-se que o etileno glicol é mais eficiente do que o glicerol para preservar a integridade das membranas espermáticas na congelação do sêmen ovino.

\section{FONTES DE AQUISIÇÃO}

a - Sigma Chemical Company. St. Louis. Mo. USA.

\section{REFERÊNCIAS BIBLIOGRÁFICAS}

CONOVER, W.J., IMAN, R.L. Rank transformation as a bridge between parametric and nonparametric statiscs. The American Statistician, v. 35, n. 3, p. 124-132, 1981.

CROSS, N.L., WATSON S.K. Assessing acrosomal status of bovine sperm using fluoresceinated lectins. Theriogenology, v. 42 , n. 1 , p. $89-98,1994$.

EMMENS, C.W., BLACKSHAW, A.W. The temperature storage of ram, bull and rabbit spermatozoa. Australian Veterinary Journal, v. 31, p. 76-79, 1950.

EVANS, G., MAXWELL, W.M.C. Salamon's artificial insemination of sheep and goats. Sydney: Butterworths, 1987, $194 \mathrm{p}$.
GARNER, D.L., PINKEL, D., JOHNSON, L.A., $\boldsymbol{e} \boldsymbol{t}$ al Assessment of spermatozoa function using dual fluorescent staining and flow cytometric analysis. Biology of Reproduction, v. 34, p. 127-138, 1986.

GREEN, D.P.L. Comparison of Hoechst 33342 and propidium iodide as fluorescent markers for sperm fusion with hamster oocytes. Journal Reproduction Fertility, v. 96, p. 581-591, 1992.

HARRISON, R.A.P., VICKERS, S.E. Use of fluorescent probes to assess membrane integrity in mammalian spermatozoa. Journal Reproduction Fertility, v. 88, n. 1, p. 343-352, 1990.

HOLT, W.V., NORTH, R.D. Partially irreversible cold-induced lipid phase transitions in mammalian sperm plasma membrane domains: freeze-fracture study. Journal of Experimental Zoology, v. 230, p. 473-483, 1984.

HOLT, W.V., NORTH, R.D. Thermotrophic phase transitions in the plasma membrane of ram spermatozoa. Journal of Reproduction Fertility, v. 78, p. 447-457, 1986.

KOVÁCS, A., FOOTE, R.H. Viability and acrossome staining of bull, boar and rabbit spermatozoa. Biotechnic Histochemistry, v. 67, n. 3, p. 119-124, 1992.

MAXWELL, W.M.C., SALAMON, S. Liquid storage of ram semen: a review. Reproduction Fertility Development, v. 5, p. 613-638, 1993.

MAXWELL, W.M.C., WATSON, P.F. Recent progress in the preservation of ram semen. Animal Reproduction Science, v. 42 , p. $55-65,1996$.

MERYMAN, H.T., WILLIAMS, R.J., DOUGLAS, M.St Freezing injury from "solution effects" and its prevention by natural or artificial cryopreservation. Cryobiology, v. 14, p. 287-302, 1977.

MOLINIA, F.C., EVANS, G., MAXWELL, W.M.C. Effect of polyols on the post-thawing motility of pellet-frozen ram spermatozoa. Theriogenology, v. 42, p. 15-23, 1994.

MORAES, C.N. Métodos alternativos para congelação, descongelação e avaliação do sêmen ovino em pellets. Santa Maria- RS, 1996. 53 p. Dissertação de Mestrado (Mestrado em Fisiopatologia da Reprodução) - Curso de Pós-graduação em Medicina Veterinária, Universidade Federal de Santa Maria, 1996.

NETER, J., WASSERMAN, W., KUTNER, M.H. Applied linear statistical models, 2. ed. Homewood, Illinois: Irwin, 1985, 1127 p.

PARKS, J.E., GRAHAM, J.K. Effects of cryopreservation procedures on sperm membranes. Theriogenology, v. 38, p. 209-222, 1992.

SALAMON, S., MAXWELL W.M.C. Frozen storage of ram semen I. Processing, freezing, thawing and fertility after cervical insemination. Animal Reproduction Science, v. 37, p. $185-249,1995$.

VÁZQUEZ, J.M., MARTÍNEZ, E., ROCA, J. et al. Use of triple stain technique for simultaneous assessment of vitality and acrosomal status in boar spermatozoa. Theriogenology, v. 38, n. 5, p. 843-852, 1992.

WINDSOR, D.P., WHITE, I.G. Mitochondrial injury to ram sperm during procedures associated with artificial insemination or frozen storage. Animal Reproduction Science, v. 40, n. 1-2, p. 43-58, 1995. 